\title{
The training intensity distribution among well-trained and elite endurance athletes
}

\section{OPEN ACCESS}

Edited by:

Jeffrey Woods,

University of Illinois at Urbana

Champaign, USA

Reviewed by:

Stephen Seiler,

University of Agder, Norway

Niels H. Secher,

University of Copenhagen, Denmark

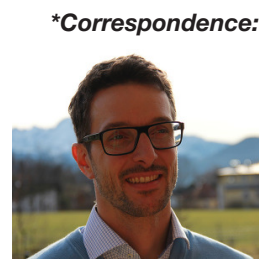

Thomas L. Stöggl, Born 1. May 1977 in Saalfelden, Austria. Associate

Professor at the University of

Salzburg, Department of Sport Science and Kinesiology since 2011.

Research Focus: Integrative biomechanics and physiology in elite

sports, with a special focus on

endurance and strength training. Personal elite sport history: 14 times Austrian Champion in cross-country skiing; Austrian Champion inline speed skating Marathon 2013; member of the Austrian cross-country skiing national team from 1993 to 2008.

Responsible for the coaches education in cross-country skiing and inline speed skating in the field of biomechanics and training science. thomas.stoeggl@sbg.ac.at

Received: 21 March 2015 Accepted: 05 October 2015 Published: 27 October 2015

Citation:

Stöggl TL and Sperlich B (2015) The training intensity distribution among well-trained and elite endurance athletes. Front. Physiol. 6:295 doi: 10.3389/fphys.2015.00295

\section{Thomas L. Stöggl ${ }^{1 *}$ and Billy Sperlich ${ }^{2}$}

${ }^{1}$ Department of Sport Science and Kinesiology, University of Salzburg, Salzburg, Austria, ${ }^{2}$ Integrative and Experimental

Training Science, Department of Sport Science, University of Würzburg, Würzburg, Germany

Researchers have retrospectively analyzed the training intensity distribution (TID) of nationally and internationally competitive athletes in different endurance disciplines to determine the optimal volume and intensity for maximal adaptation. The majority of studies present a "pyramidal" TID with a high proportion of high volume, low intensity training (HVLIT). Some world-class athletes appear to adopt a so-called "polarized" TID (i.e., significant \% of HVLIT and high-intensity training) during certain phases of the season. However, emerging prospective randomized controlled studies have demonstrated superior responses of variables related to endurance when applying a polarized TID in well-trained and recreational individuals when compared with a TID that emphasizes HVLIT or threshold training. The aims of the present review are to: (1) summarize the main responses of retrospective and prospective studies exploring TID; (2) provide a systematic overview on TIDs during preparation, pre-competition, and competition phases in different endurance disciplines and performance levels; (3) address whether one TID has demonstrated greater efficacy than another; and (4) highlight research gaps in an effort to direct future scientific studies.

Keywords: high intensity training, high volume, low intensity, polarized training, prospective, pyramidal, retrospective, threshold training

\section{INTRODUCTION}

The intensity and duration of work as well as recovery periods define overload and adaptations in athletes (Faulkner, 1968). While there appears to be consensus regarding the factors that limit endurance performance (Joyner, 1991; Coyle, 1995; Hawley and Stepto, 2001), agreement regarding the optimal volume and training-intensity distribution (TID) among elite athletes remains elusive. Achieving such consensus is important in order to maximize training adaptations and translate them into performance gains while avoiding overtraining.

Researchers have generally employed retrospective designs to analyze the TID of nationally or internationally competitive athletes in different endurance disciplines. In contrast, the number of prospective quasi-experimental or experimental studies investigating athlete responses to different TID's are small, with only limited studies examining well-trained or elite endurance athletes (Evertsen et al., 1997, 1999, 2001; Billat et al., 1999; Ingham et al., 2008, 2012; Yu et al., 2012; Stöggl and Sperlich, 2014). Articles reviewing the training intensity and duration of endurance athletes (Seiler and Tonnessen, 2009; Seiler, 2010) conclude that: (1) elite endurance athletes perform approximately $80 \%$ of their training at low intensity $(<2 \mathrm{mM}$ blood lactate) with about $20 \%$ 


\section{KEY CONCEPT 1 | Training-intensity distribution}

The intensity of exercise and its distribution over time is one essential variable for prescribing the training stimulus. The training intensity is typically divided into zones on the basis of parameters such as heart rate, blood levels of lactate, gas exchange, power output or velocity, and/or perceived exertion.

high-intensity work, (2) two high-intensity training (HIT) sessions per week suffice to induce adaptations for performance, and (3) the emphasis of HIT in highly trained athletes revealed equivocal results.

\section{KEY CONCEPT 2 | High intensity training}

High-intensity or "zone-3" training (e.g., >4 mmol lactate/L blood, >90\% maximal heart rate) involves mainly interval training, intermittent intervals, or burst-training (short, high-intensity sprints).

The percentage time spent in zones based on physiological benchmarks [derived from either heart rate (HR), gas exchange or blood lactate measurements], the session goal approach, and the session rating of perceived exertion (RPE) method have been applied to quantify the TID among endurance athletes (Seiler and Kjerland, 2006). Athletes may principally choose from one to four TIDs to induce endurance-related adaptations: (1) highvolume, low-intensity exercise (HVLIT), usually performed

\section{KEY CONCEPT 3 | High volume low intensity training}

Low-intensity training (e.g., below the first ventilatory threshold or at stable lactate concentrations $<2 \mathrm{mM}$ ) of longer duration, also referred to as long slow distance training or "zone-1" training.

below the first ventilatory threshold $\left(\mathrm{VT}_{1}\right)$ or at stable lactate concentrations of $\leq 2 \mathrm{mM}$ and referred to as "zone 1" intensity; (2) "threshold" training (THR) performed at or near the lactate

\section{KEY CONCEPT 4 | Threshold training}

Training performed mainly at an exercise intensity corresponding to the lactate threshold (e.g., $4 \mathrm{mM}$ blood lactate) or second ventilatory threshold, involves primarily continuous or intervals of moderate-intensity exercise and is often defined as "zone-2" training.

threshold (LT $\sim 4 \mathrm{mM}$ ) or second ventilatory threshold $\left(\mathrm{VT}_{2}\right)$ and designated as "zone 2" intensity; (3) HIT in "zone 3" ( $\geq 4 \mathrm{mM})$ (Seiler, 2010); or (4) a combination of the aforementioned concepts. Based on training analysis in elite rowers and cross-country skiers, a so called "polarized" TID has

\section{KEY CONCEPT 5 | Polarized training}

The polarized training consists of significant proportions of both high- and low-intensity training and only a small proportion of threshold training. The distribution between low and high intensity training is often quantified as $80: 20 \%$, or $75-80 \%$ with low intensity, $5 \%$ threshold intensity, and $15-20 \%$ as high intensity training.

been proposed (Fiskerstrand and Seiler, 2004; Seiler and Kjerland, 2006). The polarized TID comprises significant \% HVLIT time (i.e., "zone 1") and HIT time (i.e., "zone 3") compared to a low \% THR time ("zone 2"). Some investigators have separated the TID into five zones (Tonnessen et al., 2014). In contrast, the traditional TID used in the bulk of previous investigations has been composed of a "pyramidal"

\section{KEY CONCEPT 6 | Pyramidal training intensity distribution}

With the pyramidal distribution, most training is at low intensity, with decreasing proportions of threshold and high-intensity training.

structure (Holmberg, 1996), in which the majority of training time is spent in HVLIT ("zone 1"), and a decreasing proportion of training time in zones 2 and 3.

Since nearly all studies dealing with TID were based on retrospective analysis, we recently employed a randomized controlled design to investigate which TID (HVLIT vs. THR vs. HIT vs. polarized) provided the greatest response on key components of endurance performance among well-trained

\section{KEY CONCEPT 7 | Key components of endurance performance}

In connection with many endurance sports five key parameters are utilized for comparison of performance: (1) peak oxygen uptake; (2) velocity or power output at the lactate threshold; (3) work economy; (4) peak running velocity or peak power output, and (5) time to exhaustion.

athletes (Stöggl and Sperlich, 2014). We concluded that the polarized TID resulted in the greatest improvements in the majority of key endurance performance variables assessed, and THR or HVLIT did not lead to further improvements in performance. However, as numerous retrospective reports have shown conflicting results, the question regarding which TID represents the "best-practice" model for inducing performance gains-while avoiding overtraining - remains open to debate. Therefore, the aims of the present review were to: (1) summarize the main responses of different retrospective and prospective studies exploring TID; (2) provide a systematic overview of TIDs during preparation, pre-competition, and competition phases in different endurance disciplines and performance levels; (3) address whether one TID has demonstrated enhanced efficacy over another; and (4) highlight research gaps in an effort to direct future scientific studies.

\section{INTENSITY DISTRIBUTION OF ENDURANCE PERFORMANCE}

\section{Retrospective Studies}

One major problem in TID investigations lies in the difficulty of involving elite athletes in a scientific experiment. Given their already high fitness levels, introducing certain novel training programs among elite performers may not result in performance enhancement and can even lead to overtraining symptoms. Therefore, the majority of studies dealing with TID in welltrained to elite endurance athletes are based on retrospective analyses of their training (Tables 1, 2, Figure 1).

\section{Exercise-intensity Distribution during the Preparation Period}

From 1990 to 2014, the TID of elite, nationally ranked to worldclass athletes who were training in their preparation phase were reported. These athletes competed in rowing (Hartmann et al., 1990; Guellich et al., 2009), running (Robinson et al., 1991), cycling (Lucia et al., 2000), and cross-country skiing (Sandbakk et al., 2011; Tonnessen et al., 2014). Findings indicate that elite endurance athletes spend a high percentage of their TID in a 


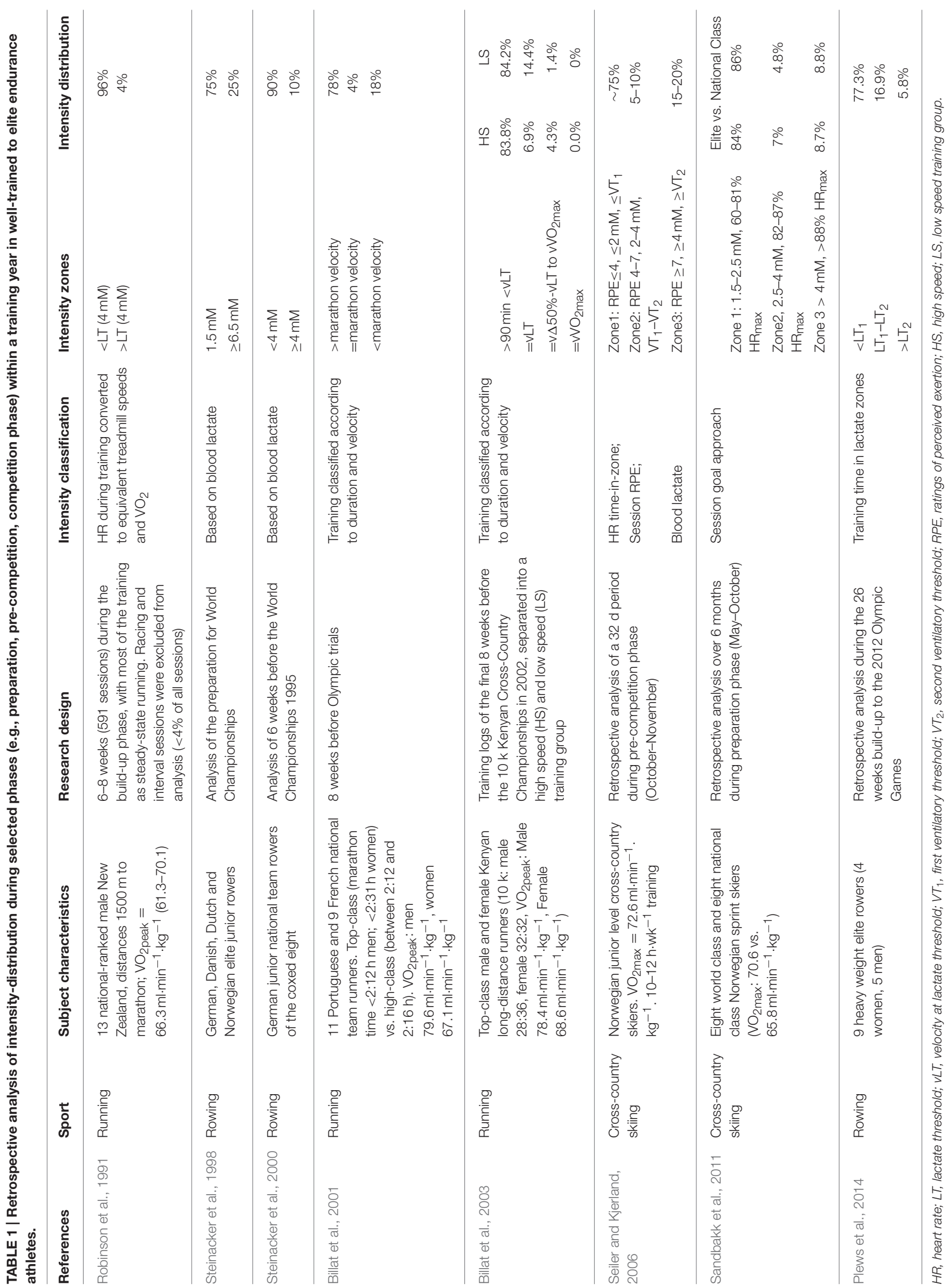




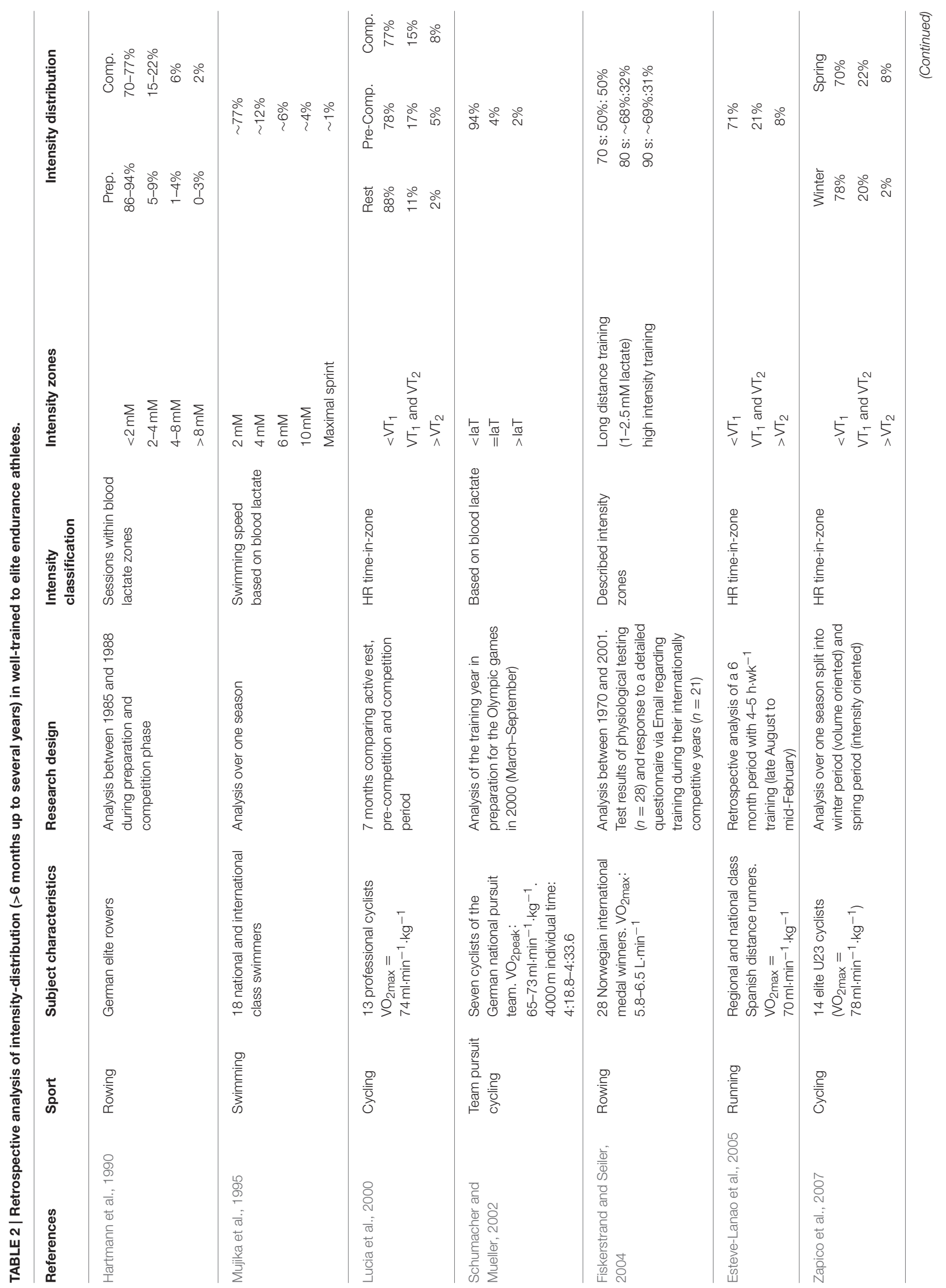




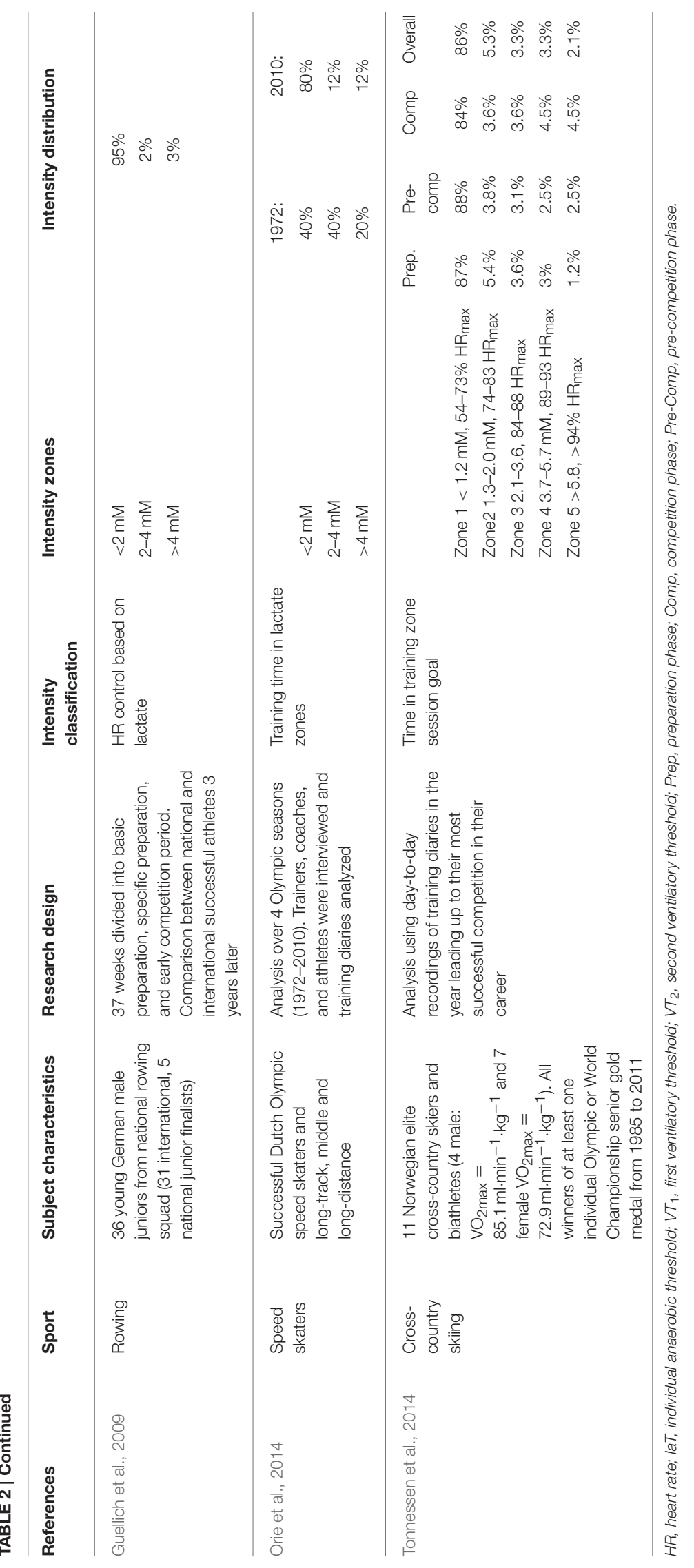


A Preparation Period

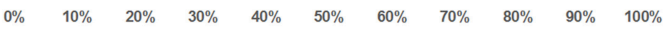

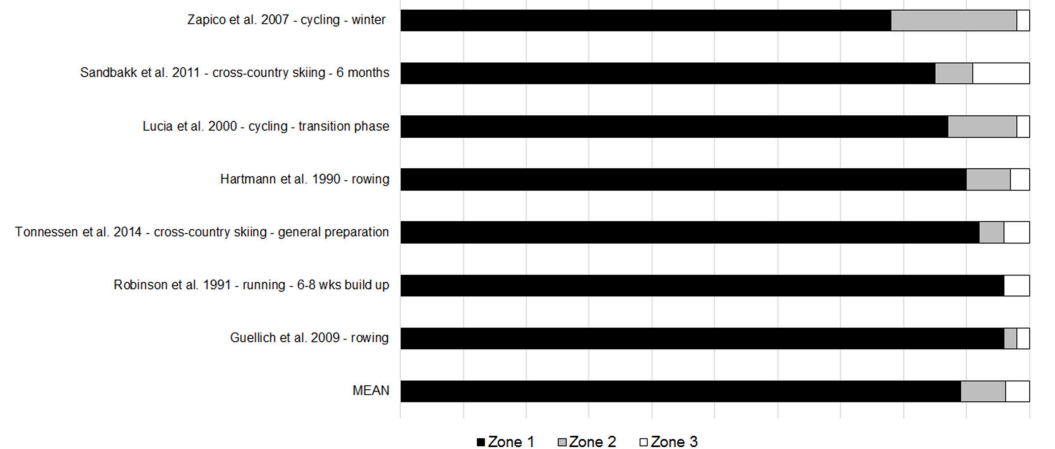

B Pre-competition Period

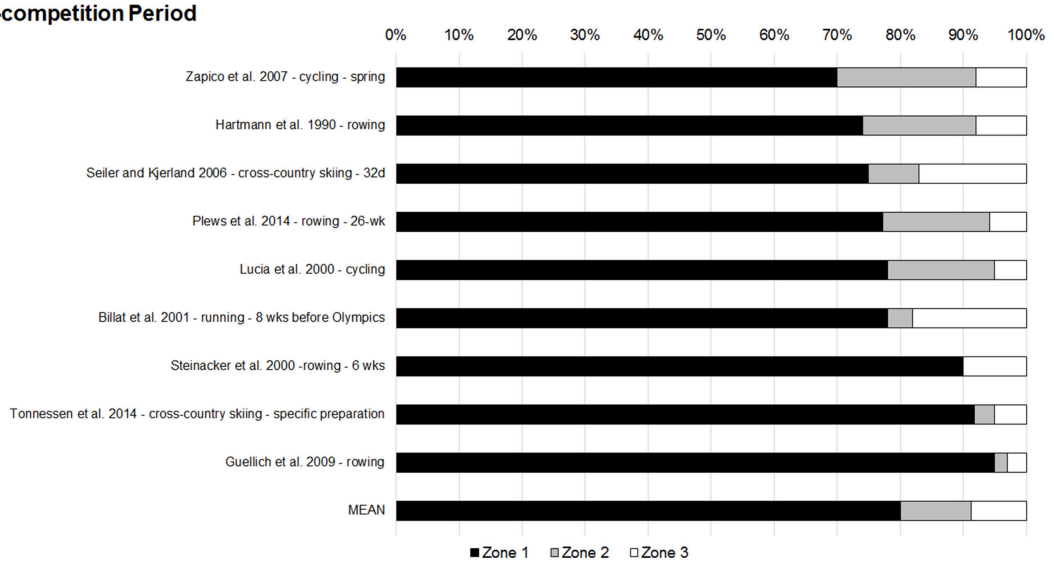

C Competition Period

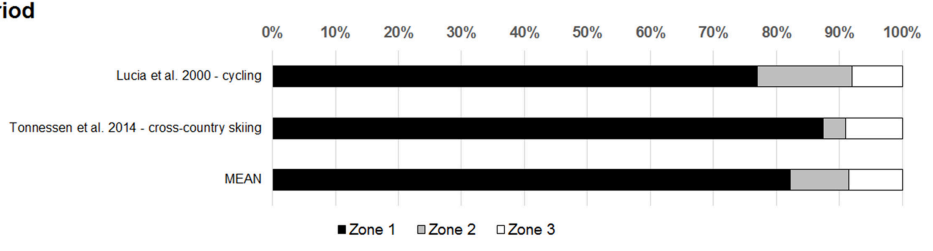

D Seasonal Analysis

Zone 1 aZone 2 aZone 3

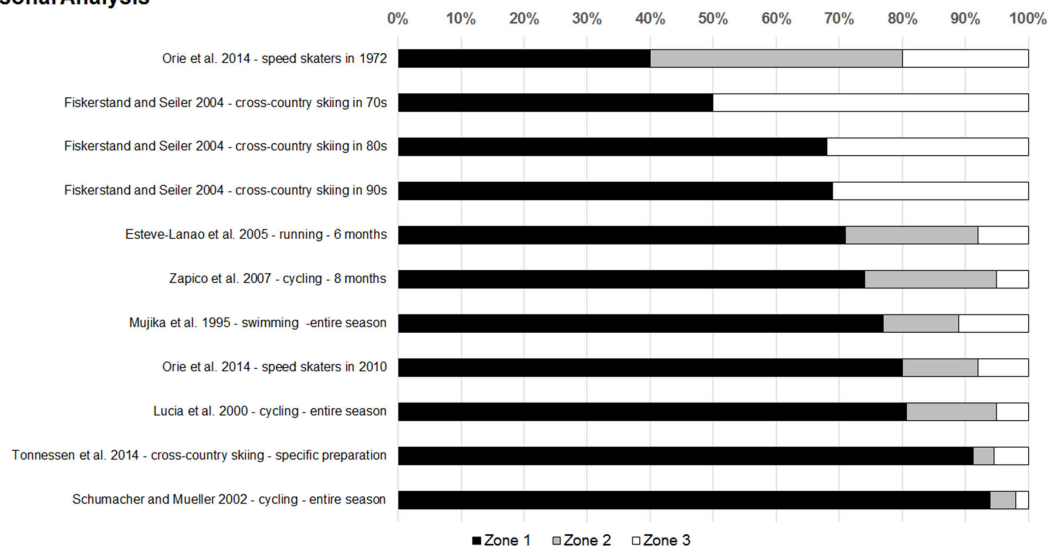

FIGURE 1 | The training-intensity distribution (i.e., percentage time spent in zone 1: <first ventilatory threshold or steady-state lactate at $\sim 2 \mathrm{mM}$; zone 2: at or near lactate threshold ( $4 \mathrm{mM})$ or second ventilatory threshold; zone 3: high-intensity training above lactate or second ventilatory threshold) in well-trained to elite endurance athletes in retrospective analyses during (A) preparation phase, (B) pre-competition phase, (C) competition phase, and (D) seasonal analysis. 
pyramid shape-that is, great portions of HVLIT with $84-95 \%$ in zone $1,2-11 \%$ in zone 2 , and $2-9 \%$ in zone 3 (Tables 1, 2, Figure 1A).

\section{Exercise-intensity Distribution before the Competition Phase}

Depending on the competition calendar the TID during the precompetition phase, may vary between endurance disciplines. The TID during pre-competition was analyzed in rowing (Hartmann et al., 1990; Steinacker et al., 2000; Guellich et al., 2009; Plews et al., 2014), running (Billat et al., 2001), cycling (Lucia et al., 2000), junior cross-country skiers (Seiler and Kjerland, 2006), and senior elite cross-country skiers and biathletes (Tonnessen et al., 2014) (Tables 1, 2, Figure 1B).

In elite rowers the TID during the pre-competition is inconclusive: in two studies the successful rowers decreased the proportion of HVLIT to $70-77 \%$ with increasing proportions of zone 2 up to $15-22 \%$, and $5.8-6 \%$ in zone 3 (Hartmann et al., 1990; Plews et al., 2014). In contrast, two studies (Steinacker et al., 2000; Guellich et al., 2009) reported very high proportions of HVLIT (90-95\%) during the pre-competition phase (i.e., 6 weeks before the 1995 World Championships).

In professional cyclists (Lucia et al., 2000) and top-class runners (Billat et al., 2001) engaged in pre-competition training, similar proportions of HVLIT were reported (78\%). The distribution of zones 2 and 3 were however, polarized (4 and 18\%) in the runners and pyramidal (17 and 5\%) in the cyclists.

Comparable with the findings in several studies with rowers (Steinacker et al., 2000; Guellich et al., 2009), elite cross-country skiers and biathletes focus on HVLIT during the pre-competition phase ( $\sim 91.8 \%$ zone $1-2$ and $8.2 \%$ zone $3-5$ ) (Tonnessen et al., 2014). However, the competitive junior cross-country skiers in the study of Seiler and Kjerland (2006) reported a polarized TID of $75,5-10$, and $15-20 \%$ in zones 1,2 , and 3, respectively, over a 32 days period during the pre-competition phase (End October, November).

Summarized, elite athletes in rowing (Hartmann et al., 1990; Steinacker et al., 2000; Guellich et al., 2009; Plews et al., 2014) and cycling (Lucia et al., 2000) reported pyramidal TID with HVLIT ranging from $78 \%$ in cycling up to $90-95 \%$ in some rowers, cross-country skiers, and biathletes. Billat et al. (2001) and Seiler and Kjerland (2006) reported a polarized TID with a greater proportion of zone 1 (75-78\%) and zone $3(15-20 \%)$ compared to zone 2 (4-10\%).

\section{Exercise-intensity Distribution during the Competition Phase}

Documentation of the TID during the competition period is rare since (a) technical equipment may not be applied during competition, (b) the TID largely depends on the amount and type of competitions (e.g., single races vs. stage races), and (c) the strategies for tapering for competitions vary widely across sports. Lucia et al. (1999) reported a pyramidal TID (70/23/7\%) during the Tour de France based on the "HR time in zone" method over 22 competition days. The exercise intensity was particularly high during the time trials and high mountain stages. Also Lucia et al. (2000) reported that elite cyclists performed approximately
$810 \mathrm{~km} \cdot \mathrm{wk}^{-1}$ (May) with a TID of $77 / 15 / 8 \%$, while elite crosscountry skiers and biathletes (Tonnessen et al., 2014) showed a higher proportion of HVLIT compared with THR and HIT ( $\sim 87.5 \%$ zone $1-2$ vs. $\sim 12.5 \%$ zone $3-5$ ) when compared with the cyclists (Figure 1C).

\section{Exercise-intensity Distribution based on Seasonal Analysis (up to 1 Year) (Table 2, Figure 1D)}

The TID covering a period of several months up to 1 year was reported in cycling (Lucia et al., 2000; Schumacher and Mueller, 2002; Zapico et al., 2007), swimming (Mujika et al., 1995), running (Esteve-Lanao et al., 2005), and cross-country skiing (Seiler and Kjerland, 2006; Tonnessen et al., 2014). Athletes from the different studies incorporated a high amount of HVLIT (70-94\%), with variations in the amount of THR (4-22\%) and HIT (2-11\%), either as pyramidal or polarized TID.

In elite cyclists a trend from a nearly complete HVLIT (preparation period) toward pyramidal TID (pre-competition, competition period) can be observed. In a 7 month longitudinal study, professional cyclists (Lucia et al., 2000) increased both the training volume (267 vs. $713 \mathrm{vs.} 810 \mathrm{~km} \cdot \mathrm{wk}^{-1}, 15,000$ total $\mathrm{km})$ and intensity from active rest $(88 / 11 / 2 \%)$ to pre-competition $(78 / 17 / 5 \%)$ and competition phases (77/15/8\%). Comparable findings were reported in U23 elite cyclists with a 78/20/2\% TID during the winter ("volume mesocycle") and 70/22/8\% during the spring ("intensity mesocycle") (Zapico et al., 2007). The recordings $\left(29,000-35,000 \mathrm{~km} \cdot \mathrm{yr}^{-1}\right)$ for the $4000 \mathrm{~m}$ team pursuit cycling world record in the year 2000 (excluding stage racing and track competitions), showed a main training focus on HVLIT with $94 \%<\mathrm{LT}, 4 \%$ around LT, and $2 \%>\mathrm{LT}$ (Schumacher and Mueller, 2002).

Comparable with the TID in the cycling studies during the pre-competition phase, regional- and national-class Spanish runners $\left(4-5 \mathrm{~h} \cdot \mathrm{wk}^{-1}\right)$ demonstrated a pyramidal TID of $71\left(<\mathrm{VT}_{1}\right), 21\left(\mathrm{VT}_{1}-\mathrm{VT}_{2}\right)$, and $8 \%\left(>\mathrm{VT}_{2}\right)$ (Esteve-Lanao et al., 2005) over a 6 month period. The TID of national and international-level swimmers revealed a pyramidal TID (although the athletes spent almost the same time in zone 2 and 3) over an entire season (77/12/11\%) (Mujika et al., 1995). The Norwegian elite cross-country skiers and biathletes analyzed during the year leading to their most successful career competition (1985-2011) (Tonnessen et al., 2014) spent 91\% of their training time in zones $1-2$ and $9 \%$ in zones $3-5$ or 77 vs. $23 \%$ when applying the session goal approach. The monthly frequency of HIT sessions and "zone 5" sessions increased from the general to the specific preparation period and remained unchanged within the competition period. From the end of the general preparation to the peaking phase, the amount of HVLIT decreased by 21\%, and HIT-especially zone 5-increased by $40 \%$. Therefore, the TID changed from an emphasis on HVLIT during preparation, toward a pyramidal TID during precompetition, and a polarized TID during the competition phase.

\section{Exercise-intensity Distribution during Long-term Analysis ( $>1$ Year) (Table 2)}

The TID across several decades was reported in rowers (Fiskerstrand and Seiler, 2004) and speed skaters (Orie et al., 2014). During the 1970s, the training volume of elite rowers 
was almost equally divided between HVLIT and HIT sessions (Fiskerstrand and Seiler, 2004). Then two major changes across time were identified: (1) training with low blood lactate $(<2 \mathrm{mM})$ increased from 30 to $50 \mathrm{~h} \cdot \mathrm{month}^{-1}$ and race pace and supramaximal intensity training $(8-14 \mathrm{mM})$ decreased from 23 to 7 $\mathrm{h} \cdot \mathrm{month}^{-1}$, and (2) total training volume increased from 924 $(600-1020) \mathrm{h} \cdot \mathrm{yr}^{-1}$ during the $1970 \mathrm{~s}$ to $966(840-1140) \mathrm{h} \cdot \mathrm{yr}^{-1}$ in the 1980s, and to $1128(1104-1200) \mathrm{h} \cdot \mathrm{yr}^{-1}$ in the 1990s ( 20\% increase). Further increase in total training volume in the 1990s did not lead to further improvement in physical capacity.

Similar to the findings by Fiskerstrand and Seiler (2004), the TID of successful male Dutch Olympic speed skaters (Orie et al., 2014) in four Olympic seasons (1972-2010; assessed by interviewing the coaches and athletes) was based on THR in $1972(40 / 40 / 20 \%)$, whereas the more recent TID was pyramidal $(\sim 80 / \sim 12 / \sim 8 \%)$ in 2010 .

\section{Prospective Studies Investigating TID Single Case or Quasi-experimental Longitudinal Studies without Control Groups (Table 3)}

Based on three studies, we conclude that an increase in HVLIT at the expense of THR leads to performance enhancements, while the exaggerated increase in HIT at the expense of HVLIT might be applied with caution.

Billat et al. (1999) examined whether one HIT session compared to three HIT sessions. $\mathrm{wk}^{-1}$ is sufficient to improve performance in four middle-distance runners. The implementation of four HVLIT, one HIT, and one THR session over 4 weeks resulted in improved running speed at maximal oxygen uptake $\left(\mathrm{VO}_{2 \max }\right)$ and running economy. A further 4 weeks intensification, including two HVLIT, three HIT, and one THR session each week, showed no additional performance benefit, but increased subjective muscle stress, reduced sleep quality, and increased plasma epinephrine, all indicators of impending overtraining.

Altering TID from a THR-emphasis toward a more polarized or pyramidal TID showed improvements in competition performance and physiological capability. In the case study of a male international $1500 \mathrm{~m}$ runner (PB 3:38.9 min:s), HVLIT was performed within the first year above the coach's prescribed level and "tempo" training at an excessively high intensity. In the second year, HVLIT $\left(<80 \% \mathrm{VO}_{2 \max }\right)$ increased from 20 to $55 \%$ and intense training at $80-90 \% \mathrm{VO}_{2 \max }$ and $90-$ $100 \% \mathrm{VO}_{2 \max }$ was reduced from approximately 42 to $20 \%$ and 20 to $10 \%$, respectively. Furthermore, a concomitant increase in the proportion of HIT $\left(100-130 \% \mathrm{vVO}_{2 \max }\right)$ from 7 to $10 \%$ was observed. This training modification coincided with improvements in physiological capability (increase in $\mathrm{VO}_{2 \max }$ from 72 to $79 \mathrm{ml} \cdot \mathrm{min}^{-1} \cdot \mathrm{kg}^{-1}$ ) and performance improvements (3:38.9 to 3:32.4 over $1500 \mathrm{~m}$ ) (Ingham et al., 2012).

The 1 year adaptation of a THR emphasized (41/51/7\%) vs. a polarized $(86 / 5 / 10 \%)$ TID were evaluated in nine Chinese top-level sprint speed skaters $(500$ and $1000 \mathrm{~m}$ ) and their performances at national competitions, World Cups, and the Olympics (Yu et al., 2012). The overall training durations and frequencies were similar across the two seasons, with THR constituting $50 \%$ of the training time $(41 / 51 / 7 \%)$ and with
POL 1 year later only 5\% (86/5/10\%). The increase in HVLIT, the reduction of THR from 50 to $5 \%$, and the increase in HIT led to $2-4 \%$ improvements in the $500 \mathrm{~m}$ and $1000 \mathrm{~m}$ events.

\section{Randomized Controlled Studies (Table 4)}

The focus of the nine studies manipulating TID was mainly to compare the change in performance and/or adaptation to three different TID's including: THR-emphasized training, HVLITemphasized training, and polarized TID. In the majority of studies, recreational or sub-elite athletes were investigated. All experimental studies reported increased endurance performance, however, in most of the studies the polarized or HVLIT-emphasized TID resulted in the greatest responses of various endurance performance variables (Esteve-Lanao et al., 2007; Ingham et al., 2008; Neal et al., 2013; Munoz et al., 2014; Stöggl and Sperlich, 2014).

Esteve-Lanao et al. (2007) were among the first to conduct experimental randomized controlled studies assessing the effects of 5 months increased or decreased HVLIT on endurance performance. Twelve sub-elite Spanish runners were randomly assigned to two separate groups performing equal amounts of HIT $\left(8.4 \%\right.$ of training $>\mathrm{VT}_{2}$ ). Although the two groups varied in the amount of HVLIT (group 1: $81 \%$, group 2: 67\%) vs. THR (group 1: 12\%; group 2: $25 \%$ ), they achieved equal total training loads (TRIMP scores). A polarized TID $(74 / 11 / 15 \%)$ in the group with emphasized HVLIT was revealed with the session goal approach. The improvement in $10.4 \mathrm{~km}$ running was greater in the group emphasizing HVLIT (-157 vs. -122 s). If there is sufficient training time, it is advised to design an "easy-hard" rather than a "moderately high-hard" load distribution training approach.

In line with the Esteve-Lanao et al. (2007) study, experienced national standard British rowers performed either 12 weeks of $\operatorname{HVLIT}(98 \% \leq \mathrm{LT})$ or mixed-intensity training $(72 \% \leq$ LT; $28 \%$ between LT and $\mathrm{VO}_{2 \text { peak }}$ ) (Ingham et al., 2008). Whereas, both groups improved similarly in terms of their performance $\left(\mathrm{VO}_{2 \text { peak }}, 2000 \mathrm{~m}\right.$ ergometer time trial), HVLIT improved performance at LT to a greater extent than in the mixed training group.

Neal et al. (2013) analyzed the molecular adaptation resulting from 6 weeks of polarized (80/0/20\%) vs. THR (57/43/0\%) TID in 12 male cyclists. In both groups, $40 \mathrm{~km}$ time trial performance, peak power output, power at LT, monocarboxylate-transporter 4 and high-intensity exercise capacity all increased; however, improvements were greater with polarized TID concerning peak power output ( 8 vs. $3 \%$ ), power at LT (9 vs. $2 \%$ ), and highintensity capacity ( 85 vs. $37 \%$ ), despite greater total training volume in THR ( $458 \mathrm{vs} .381 \mathrm{~min} \cdot \mathrm{wk}^{-1}$ ).

Munoz et al. (2014) manipulated the TID in 30 recreational runners randomly assigned to a 10 weeks training program (56 sessions $\left.\cdot \mathrm{wk}^{-1}\right)$ emphasizing polarized training $(77 / 3 / 20 \%)$ or THR (46/35/19\%) with equal volume in zone 3 (i.e., 2 weekly sessions at $\geq 85 \% \mathrm{VO}_{2 \max }$ ) and equal in training load (TRIMP). Both groups increased their $10 \mathrm{~km}$ performance by 5.0 vs. $3.5 \%$ for polarized vs. THR TID. In a sub-analysis of selected athletes with TIDs emphasizing either zone 1 in the polarized group or 
TABLE 3 | Non-experimental longitudinal or single case studies comparing different intensity-distribution in well-trained to elite endurance athletes.

\begin{tabular}{|c|c|c|c|c|c|c|c|}
\hline References & Sport & Subject characteristics & Research design & Intensity & Intensity zones & Intens & listribution \\
\hline $\begin{array}{l}\text { Billat et al., } \\
1999\end{array}$ & Running & $\begin{array}{l}\text { Eight endurance-trained } \\
\text { male middle and long } \\
\text { distance runners ( } 1500 \mathrm{~m} \text { to } \\
\text { half-marathon). Training } 6 \\
\text { sessions. } \mathrm{wk}^{-1}\end{array}$ & $\begin{array}{l}\text { Non-experimental longitudinal } \\
\text { study with } 4 \text { weeks using } 4 \\
\text { HVLIT, } 1 \text { LT and } 1 \mathrm{HIT} \text { session ( } 5 \\
\times \mathrm{VVO}_{2 \mathrm{max}} \text { with } 50 \% \text { of } \\
\text { tVO2max) followed by } 4 \text { weeks } \\
\text { of } 2 \mathrm{HVLIT,} 1 \mathrm{LT} \text {, and } 3 \mathrm{HIT} \\
\text { sessions }\end{array}$ & $\begin{array}{l}\text { Based on running } \\
\text { speeds in } \% \mathrm{vO}_{2 \max }\end{array}$ & $\begin{array}{l}\text { HVLIT }(60-70 \% \\
\text { VVO }_{2 \max } \\
\text { OBLA: } 4 \mathrm{mM} \\
\text { HIT: } V \mathrm{VO}_{2 \max }\end{array}$ & $\begin{array}{l}\text { LOW } \\
4 \\
1 \\
1\end{array}$ & $\begin{array}{l}\text { High } \\
3 \\
1 \\
2\end{array}$ \\
\hline $\begin{array}{l}\text { Ingham } \\
\text { et al., } 2012\end{array}$ & Running & $\begin{array}{l}\text { One international } 1500 \mathrm{~m} \\
\text { runner (PB 3:38.9 min:s; } \\
\mathrm{VO}_{2 \mathrm{max}}: 70.5- \\
79.6 \mathrm{ml} \cdot \mathrm{min}^{-1} \cdot \mathrm{kg}^{-1} \text { ) }\end{array}$ & $\begin{array}{l}\text { Single case study over } 2 \text { years. } \\
\text { In the first year the HVLIT was } \\
\text { performed above the prescribed } \\
\text { level and tempo training at an } \\
\text { excessively high intensity. } \\
\text { Second year HVLIT was } \\
\text { increased from } 20 \text { to } 55 \% \text {, LT } \\
\text { and HIT was reduced from } 42 \text { to } \\
20 \% \text { and } 20 \text { to } 10 \% \text {, while the } \\
\text { highest intensity was increased } \\
\text { from } 7 \text { to } 10 \%\end{array}$ & $\begin{array}{l}\text { Based on respective } \\
\text { speed expressed as \& } \\
\mathrm{VVO}_{2 \max }\end{array}$ & $\begin{array}{l}\text { HVLIT: }<80 \% \mathrm{VVO}_{2 \max } \\
\text { Tempo: } 80-90 \% \\
\mathrm{VVO}_{2 \max } \\
\mathrm{HIT:} 90-100 \% \\
\mathrm{VVO}_{2 \max } \\
\text { Supramaximal: } \\
100-130 \% \mathrm{VVO}_{2 \max }\end{array}$ & $\begin{array}{l}\text { Year1 } \\
\sim 20 \% \\
\sim 44 \% \\
\sim 20 \% \\
\sim 16 \%\end{array}$ & $\begin{array}{l}\text { Year2 } \\
\sim 55 \% \\
\sim 20 \% \\
\sim 8 \% \\
\sim 17 \%\end{array}$ \\
\hline $\begin{array}{l}\text { Yu et al., } \\
2012\end{array}$ & $\begin{array}{l}\text { Speed } \\
\text { skaters }\end{array}$ & $\begin{array}{l}\text { Nine Chinese top-level } \\
\text { sprint skaters ( } 500 \mathrm{~m} \text { and } \\
1000 \mathrm{~m} \text { ) all performing at } \\
\text { World Cup and Olympic } \\
\text { competitions during } \\
\text { 2004-2006 }\end{array}$ & $\begin{array}{l}\text { Non-experimental longitudinal } \\
\text { study comparing } 1 \text { year THR } \\
\text { training vs. } 1 \text { year polarized } \\
\text { training. Performances during } \\
\text { national, World Cup and Olympic } \\
\text { competitions and blood lactate } \\
\text { after competitions were analyzed }\end{array}$ & $\begin{array}{l}\text { HR time-in-zone based } \\
\text { on lactate testings }\end{array}$ & $\begin{array}{l}\text { Low: }<2 \mathrm{mM} \\
\text { Moderate: } 2-4 \mathrm{mM} \\
\text { High: }>4 \mathrm{mM}\end{array}$ & $\begin{array}{c}\text { Year1 } \\
41 \% \\
51 \% \\
7 \%\end{array}$ & $\begin{array}{c}\text { Year2 } \\
86 \% \\
5 \% \\
10 \%\end{array}$ \\
\hline
\end{tabular}

HVLIT, high volume low intensity training; LT, lactate threshold; HIT, high intensity training; HR, heart rate; $V O_{2 m a x}$, velocity at maximal oxygen uptake.

zone 2 in the THR group, the polarized TID showed greater improvements $(+7.0 \%)$ compared with THR $(+1.6 \%)$.

Stöggl and Sperlich (2014) explored the response of HVLIT $(83 / 16 / 1 \%)$ vs. THR (46/54/0\%) vs. HIT (43/0/57\%) vs. polarized TID (68/6/26\%) on key components of endurance performance in 48 well-trained runners, cyclists, triathletes and cross-country skiers. While all four groups increased time to exhaustion, the polarized TID increased $\mathrm{VO}_{2 \text { peak }}(+11.7 \%)$, time to exhaustion $(+17.4 \%)$, and peak performance $(+5.1 \%)$ to the greatest extent. Performance at $4 \mathrm{mM}$ increased after polarized TID $(+8.1 \%)$ and HIT $(+5.6 \%)$, with no change in the other groups. HIT resulted in decreased body mass $(-3 \mathrm{~kg})$ and increased $\mathrm{VO}_{2 \text { peak }}$ $(+4.8 \%)$. Exclusive emphasis of THR or HVLIT did not lead to further improvements in endurance performance in well-trained athletes.

Evertsen et al. (1997, 1999, 2001) randomly assigned 20 welltrained Norwegian cross-country skiers for 5 months to HVLIT vs. a HIT/THR emphasized TID. The HVLIT group spent $86 \%$ at an intensity $<1.5 \mathrm{mM}$ ( 7 sessions $\cdot \mathrm{wk}^{-1}$ with an increase from 10 to $16 \mathrm{~h} \cdot \mathrm{wk}^{-1}$ ) and $2-3$ sessions $\cdot \mathrm{wk}^{-1}$ HIT (14\%), while the HIT/THR group demonstrated $83 \%$ HIT/THR at 3-4 mM (12 $\mathrm{h} \cdot \mathrm{wk}^{-1}$ ) and $17 \%$ HVLIT as recovery. Despite a $60 \%$ increase in training volume in the HVLIT group and approximately four times more training at intensity close to LT in the HIT/THR group, physiological and performance changes were modest in both groups. In contrast to other studies (Ingham et al., 2008; Stöggl and Sperlich, 2014), greater improvements in performance (e.g., running speed at LT and performance in a 20 min run) were found in the HIT/THR group compared with HVLIT.

Seiler et al. (2013) analyzed the performance adaptations of different types of high intensity interval training. Thirtyfive recreational cyclists were randomized to four training groups with equivalent training the two previous months $\left(\sim 6 \mathrm{~h} \cdot \mathrm{wk}^{-1}, \sim 1.5\right.$ session $\left.\cdot \mathrm{wk}^{-1}\right)$. The HVLIT group trained 4-6 sessions. $\mathrm{wk}^{-1}$, and the three HIT groups trained two sessions. $\mathrm{wk}^{-1}$ with either $4 \times 4 \mathrm{~min}\left(94 \% \mathrm{HR}_{\max }\right), 4 \times 8 \mathrm{~min}$ $\left(90 \% \mathrm{HR}_{\max }\right)$, or $4 \times 16 \mathrm{~min}\left(88 \% \mathrm{HR}_{\max }\right)$ plus $2-3$ sessions $\cdot \mathrm{wk}^{-1}$ HVLIT. The $4 \times 8 \mathrm{~min}$ interval group induced greater average gains in $\mathrm{VO}_{2 \text { peak }}$, power at $\mathrm{VO}_{2 \text { peak }}$, and power at $4 \mathrm{mM}$. Subjects without interval training experience before the intervention tended to achieve greater average improvements in $\mathrm{VO}_{2 \text { peak }}$, peak power output, and power at $4 \mathrm{mM}$ compared with subjects reporting 1-1.5 HIT sessions. $\mathrm{wk}^{-1}$. All three interval training groups tended to improve in physiological capacity after the training period, while the HVLIT group remained relatively unchanged (with the exception of a significant increase in power at $4 \mathrm{mM}$ ), despite similar or slightly higher total training volumes $\left(8.5 \mathrm{~h} \cdot \mathrm{wk}^{-1}\right.$ vs. $\left.5.7-7.6 \mathrm{~h} \cdot \mathrm{wk}^{-1}\right)$.

\section{METHODOLOGICAL CONSIDERATIONS}

Although the authors are aware that the investigations summarized in this review vary regarding the endurance disciplines, athletic level, duration of observation, time 


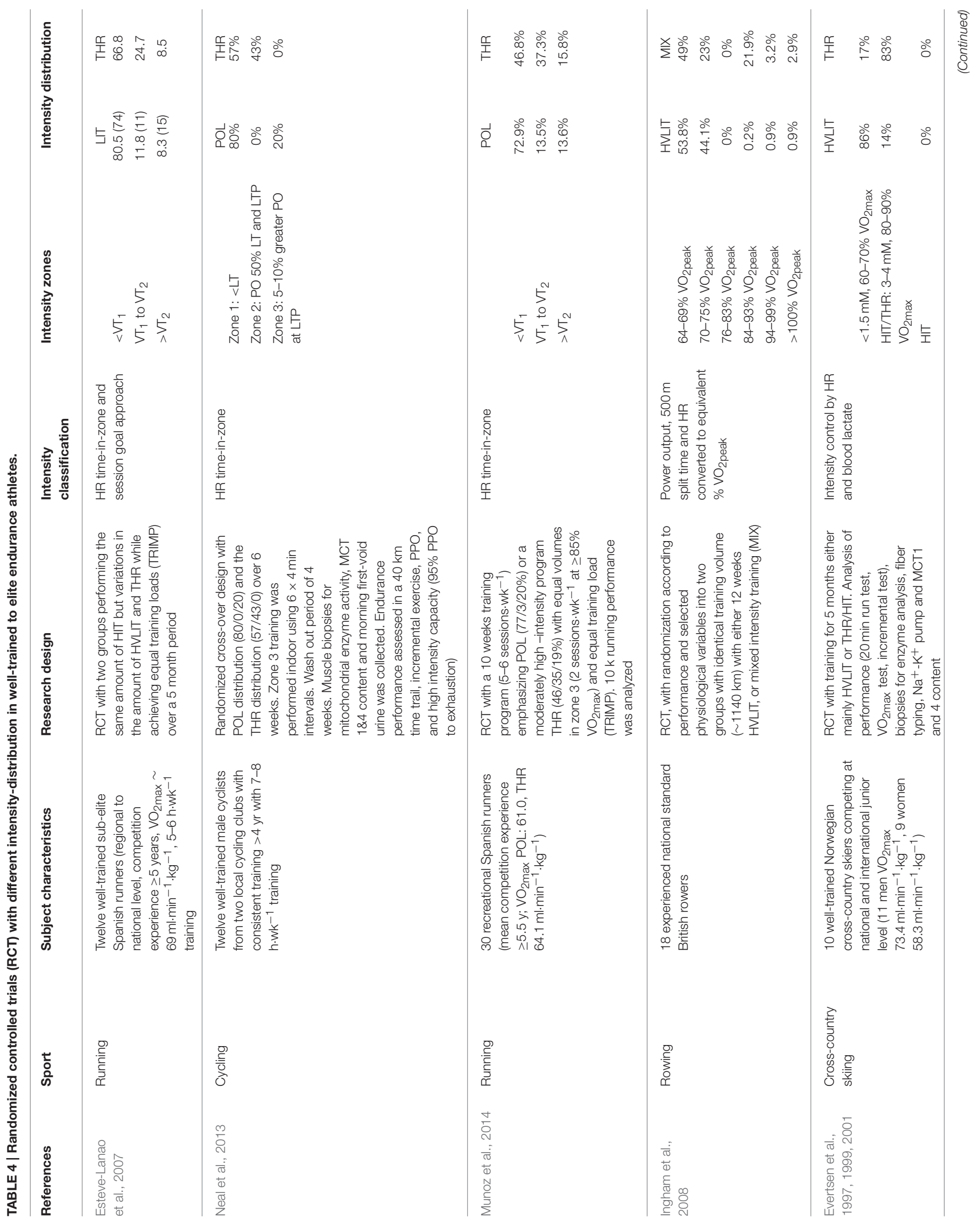




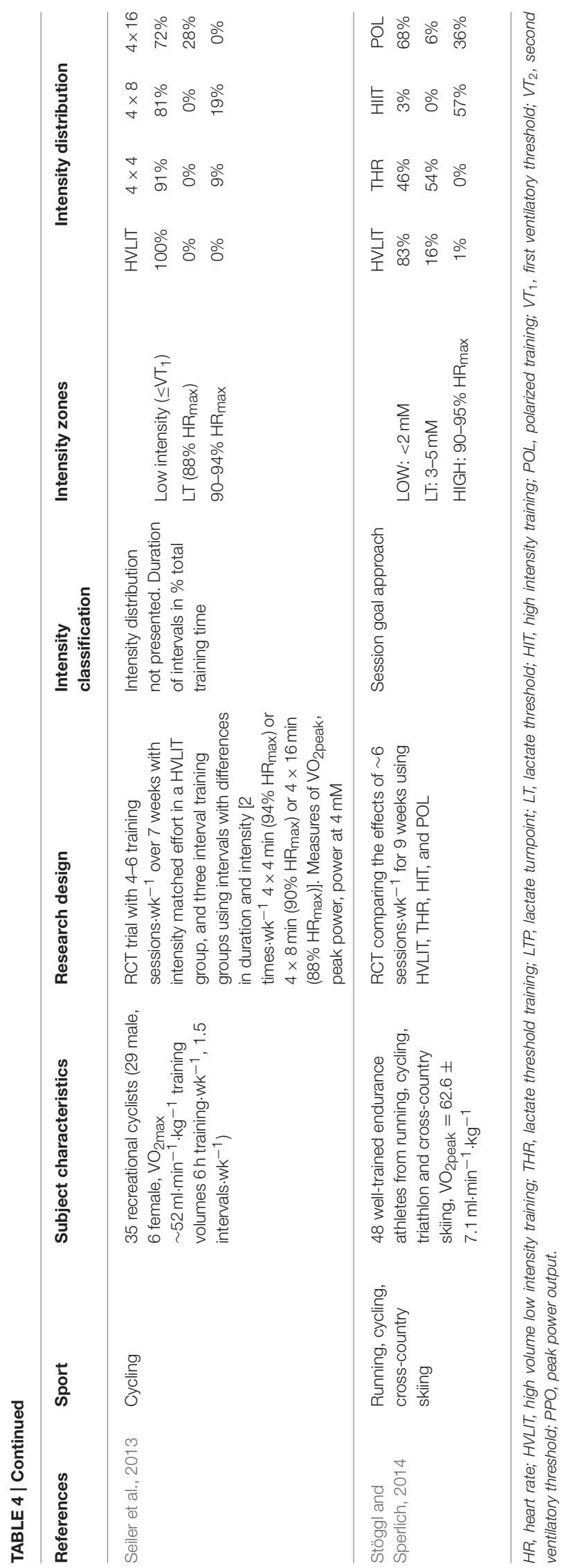

of season (preparation, pre-competition, or competition phase) and TID methodology, the present data show no uniform TID pattern among the different endurance disciplines (Figure 1).

The methodology incorporated in the retrospective analysis to compare the TID between disciplines might produce discrepancies in numbers. The intensity of endurance exercise is frequently defined as percentage of $\mathrm{HR}_{\max }$ or $\mathrm{VO}_{2 \max }$ or blood lactate concentration. The percentages of for example, $\mathrm{VO}_{2 \max }$ have been shown to lead to inhomogeneous metabolic strain as indicated by the large variability of blood lactate responses (Scharhag-Rosenberger et al., 2010), and therefore may lead to imprecise assignment to the intensity zones during prolonged exercise.

Elite endurance athletes also implement strength training and speed training in their conditioning training. Since these training forms incorporate short $(<30 \mathrm{~s})$, very intense, anaerobic bouts, the continuous measurement of for example HR (due to inertia of the cardio-respiratory system at the onset of intense exercise) may preclude exact quantification of the intensity zone for this part of training. In this context, other methods, such as the "session RPE method" or the "session goal approach" (Seiler and Kjerland, 2006) might be applied. For other candidate biomarkers to quantify training load and understand fatigue in athletes we refer to Halson (2014).

\section{INTENSITY DISTRIBUTION AMONG ENURANCE ATHLETES}

Most retrospective studies report a pyramidal TID, with extensive HVLIT ( $>70 \%$ ), less time in zone 2 , and very little time spent in zone 3 , independent of the time of season. Three studies on polarized TID involving cross-country skiers during different phases of the season (Seiler and Kjerland, 2006; Sandbakk et al., 2011; Tonnessen et al., 2014) and one on marathon runners (Billat et al., 2001) were found.

Athletes favor HVLIT, since when the training volume is high, low intensity training $\left(<2 \mathrm{mM}\right.$ or $\left.\sim 55-85 \% \mathrm{HR}_{\max }\right)$ is more tolerable (Hartmann et al., 1990). Despite athletes' preference for low intensity training the majority of coaches favored higher intensity [2.5-4 mM (THR)], mainly for theoretical reasons (e.g., Fritsch, 1985, 1986; Nolte, 1986). Since the amount of HVLIT has been linked to improved race performance (Hagerman and Staron, 1982; Steinacker, 1993; Esteve-Lanao et al., 2005; Seiler and Kjerland, 2006), the necessity of HVLIT in achieving physiological adaptations for gains in performance has been pointed out in longitudinal observations and experimental designs (Esteve-Lanao et al., 2005, 2007; Zapico et al., 2007; Ingham et al., 2008). However, when the amount of HVLIT by elite athletes is doubled, no further improvement in performance is evident (Costill et al., 1991), and the athletes mood may be negatively affected (Raglin, 1993). Therefore, for elite endurance athletes with high amounts of HVLIT, the ability to distribute the training intensity optimally may be paramount to both success and counteracting non-functional overreaching (Fiskerstrand and Seiler, 2004). 
The longitudinal retrospective observations (Fiskerstrand and Seiler, 2004; Orie et al., 2014) and quasi-experimental designs (Ingham et al., 2012; Yu et al., 2012), revealed a THR-emphasized TID in recent decades. Overdoing THR by $>20 \%$ through reducing HVLIT may exert a negative impact on the autonomic nervous system (Chwalbinska-Moneta et al., 1998; Esteve-Lanao et al., 2007), with no further adaptation (Esteve-Lanao et al., 2007; Guellich and Seiler, 2010; Ingham et al., 2012; Yu et al., 2012; Neal et al., 2013; Stöggl and Sperlich, 2014). In fact, THR training places greater demands on carbohydrate fueling, leading to restricted training time due to limited glycogen storing (Beneke et al., 2011). However, THR may be more applicable for untrained and/or recreational individuals (Kindermann et al., 1979; Yoshida et al., 1982; Denis et al., 1984; Keith et al., 1992; Takeshima et al., 1993; Londeree, 1997; Gaskill et al., 2001). In some disciplines however, displaying a pyramidal TID, THR was thought to be a fundamental part of the training program (7$22 \%$ ) of elite endurance athletes or in distinct phases of the season (Hartmann et al., 1990; Lucia et al., 2000; Esteve-Lanao et al., 2005; Zapico et al., 2007; Sandbakk et al., 2011; Plews et al., 2014).

The various responses to HIT have been investigated extensively, showing rapid adaptions of various tissues and performance indexes (Lindsay et al., 1996; Weston et al., 1997; Stepto et al., 1999; Laursen, 2010) involving aerobic and anaerobic energy demands (Laursen and Jenkins, 2002; Laursen, 2010; Sperlich et al., 2011). The molecular events (Laursen, 2010), fueling strategies (Burke, 2010), hydration (Maughan and Shirreffs, 2010), psychological skills (Birrer and Morgan, 2010), and overtraining prevention (Kellmann, 2010) in connection with HIT have been previously described in detail.

Runners who have prioritized HIT instead of THR into their HVLIT- training have been reported to perform better (Billat et al., 2003), a result which was corroborated in a prospective study (Stöggl and Sperlich, 2014). Approximately two HIT sessions. $\mathrm{wk}^{-1}$ have been proposed to stimulate performance adaptations without inducing chronic stress (Seiler, 2010). While it was shown that an increase from one to three HIT sessions per week was not accompanied with further performance benefits, such an increase did result in greater subjective muscle stress, plasma epinephrine, and reduced sleep quality, all indicators of impending overtraining (Billat et al., 1999).

Although there are numerous time-efficient adaptations and health benefits associated with HIT, there is evidence that individuals will need to feel physically capable and adequately motivated to perform and maintain high intensity exercise (Hardcastle et al., 2014). Additionally, condensed HIT over a longer period ( 9 weeks) may lead to a loss in body mass in well-trained athletes (Stöggl and Sperlich, 2014) which may also negatively impact health.

Training adaptation is subject to high inter-individual response (Bouchard et al., 1986), and disciplines with high eccentric forces, high force impacts (e.g., running), and chronic muscle damage will not necessarily exhibit similar TID when compared to disciplines with lower eccentric impact (e.g., swimming, cycling, rowing) because recovery and low-intensity exercise might be less prominent. From this point of view the same TID will in all likelihood induce different adaptations among individuals, even if they behave and exercise in an "elite" manner.

Although the number of retrospective studies reporting a HVLIT or pyramidal based TID is substantial compared to polarized TID in well-trained to elite endurance athletes (Tables 1-4, Figure 1), the findings from various prospective studies ( $\leq 5$ months training intervention), suggest that a polarized TID results in superior training and performance responses compared to HVLIT and THR in some endurance disciplines and certain phases of the season. Since, variation of the training stimuli is a critical aspect of effective training (Kiely, 2010, 2012), switching from a long-term unidirectional training stressor (e.g., HVLIT) to another training stressor that provides a substantial increase in the amount of HIT (e.g., polarized TID) may prove fruitful. The optimal type of periodization model however, remains open for debate (Issurin, 2010; Kiely, 2010, 2012). For instance, it is noteworthy that the effects of an inverse pyramidal or inverse polarized TID (applying a high amount of HIT with lower portion of HVLIT-e.g., 20:80), or exclusive HIT for a longer period ( $>9$ weeks) has not been analyzed. Based on the experience of our previous investigation (Stöggl and Sperlich, 2014), researchers-especially those conducting prospective studies - will have to face the question which TID (in combination with different periodization models) is superior in athletic and health seeking populations.

Technical advancements integrating different internal (e.g., HR, oxygenation via near-infrared spectroscopy, sleep analysis, breathing pattern, HR variability, hand-held analysis of saliva and blood, questionnaires, etc.) and external (power output, GPS-based distance and speed, accelero- and inclinometer, etc.) sensor technologies that enable biological monitoring at a distance (Chan et al., 2012) will further enhance the estimation of individual athletes' optimal TID in a timely manner. Yet, the question remains: which data are the best foundation for quantifying TID?

In summary, most retrospective studies on well-trained to elite endurance athletes report a pyramidal TID, with a large proportion of HVLIT. Polarized TID has been proven to be an effective strategy for some elite athletes during certain phases of the season. However, experimental studies lasting 6 weeks to 5 months demonstrate superior responses to polarized TID, especially when compared with TID that emphasizes THR or HVLIT. As pointed out, the combination of HVLIT with HIT may improve endurance performance with potentially less autonomic and hormonal stress and boredom. The reasons for the non-uniform TID among endurance disciplines may arise from differences in methodology in retrospective analyses and/or high inter-individual variation in the training response. Furthermore, the long-term effects of different forms of TID (e.g., inverse pyramidal or inverse polarized or exclusive HIT) with different patterns of periodization on well-trained to elite endurance athletes, have yet to be characterized. Consequently, an "optimal" TID cannot be identified, and future prospective randomized investigations conducted over extended timeperiods will have to be designed to address this question. 


\section{REFERENCES}

Beneke, R., Leithauser, R. M., and Ochentel, O. (2011). Blood lactate diagnostics in exercise testing and training. Int. J. Sports Physiol. Perform. 6, $8-24$.

Billat, V. L., Demarle, A., Slawinski, J., Paiva, M., and Koralsztein, J. P. (2001). Physical and training characteristics of top-class marathon runners. Med. Sci. Sports Exerc. 33, 2089-2097. doi: 10.1097/00005768-20011200000018

Billat, V. L., Flechet, B., Petit, B., Muriaux, G., and Koralsztein, J. P. (1999). Interval training at VO2max: effects on aerobic performance and overtraining markers. Med. Sci. Sports Exerc. 31, 156-163. doi: 10.1097/00005768-19990100000024

Billat, V. L., Lepretre, P. M., Heugas, A. M., Laurence, M. H., Salim, D., and Koralsztein, J. P. (2003). Training and bioenergetic characteristics in elite male and female Kenyan runners. Med. Sci. Sports Exerc. 35, 297-304. discussion: 305-296. doi: 10.1249/01.MSS.0000053556.59992.A9

Birrer, D., and Morgan, G. (2010). Psychological skills training as a way to enhance an athlete's performance in high-intensity sports. Scand. J. Med. Sci. Sports 20(Suppl. 2), 78-87. doi: 10.1111/j.1600-0838.2010.01188.x

Bouchard, C., Lesage, R., Lortie, G., Simoneau, J. A., Hamel, P., Boulay, M. R., et al. (1986). Aerobic performance in brothers, dizygotic and monozygotic twins. Med. Sci. Sports Exerc. 18, 639-646. doi: 10.1249/00005768-19861200000006

Burke, L. M. (2010). Fueling strategies to optimize performance: training high or training low? Scand. J. Med. Sci. Sports 20(Suppl. 2), 48-58. doi: 10.1111/j.16000838.2010.01185.x

Chan, M., Esteve, D., Fourniols, J. Y., Escriba, C., and Campo, E. (2012). Smart wearable systems: current status and future challenges. Artif. Intell. Med. 56, 137-156. doi: 10.1016/j.artmed.2012.09.003

Chwalbinska-Moneta, J., Kaciuba-Uscilko, H., Krysztofiak, H., Ziemba, A., Krzeminski, K., Kruk, B., et al. (1998). Relationship between EMG, blood lactate, and plasma catecholamine tresholds during graded exercise in men. J. Physiol. Phyrmacol. 49, 433-441.

Costill, D. L., Thomas, R., Robergs, R. A., Pascoe, D., Lambert, C., Barr, S., et al. (1991). Adaptations to swimming training: influence of training volume. Med. Sci. Sports Exerc. 23, 371-377. doi: 10.1249/00005768-199103000-00017

Coyle, E. F. (1995). Integration of the physiological factors determining endurance performance ability. Exerc. Sport Sci. Rev. 23, 25-63. doi: 10.1249/00003677199500230-00004

Denis, C., Dormois, D., and Lacour, J. R. (1984). Endurance training, VO2 max, and OBLA: a longitudinal study of two different age groups. Int. J. Sports Med. 5, 167-173. doi: 10.1055/s-2008-1025899

Esteve-Lanao, J., Foster, C., Seiler, K. S., and Lucia, A. (2007). Impact of training intensity distribution on performance in endurance athletes. J. Strength Cond. Res. 21, 943-949. doi: 10.1519/R-19725.1

Esteve-Lanao, J., San Juan, A. F., Earnest, C. P., Foster, C., and Lucia, A. (2005). How do endurance runners actually train? Relationship with competition performance. Med. Sci. Sports Exerc. 37, 496-504. doi: 10.1249/01.MSS.0000155393.78744.86

Evertsen, F., Medbo, J. I., and Bonen, A. (2001). Effect of training intensity on muscle lactate transporters and lactate threshold of cross-country skiers. Acta Physiol. Scand. 173, 195-205. doi: 10.1046/j.1365-201X.2001. 00871.x

Evertsen, F., Medbo, J. I., Jebens, E., and Gjovaag, T. F. (1999). Effect of training on the activity of five muscle enzymes studied on elite cross-country skiers. Acta Physiol. Scand. 167, 247-257. doi: 10.1046/j.1365-201x.1999. 00607. $\mathrm{x}$

Evertsen, F., Medbo, J. I., Jebens, E., and Nicolaysen, K. (1997). Hard training for 5 mo increases $\mathrm{Na}(+)-\mathrm{K}+$ pump concentration in skeletal muscle of crosscountry skiers. Am. J. Physiol. 272, R1417-R1424.

Faulkner, J. A. (1968). New perspectives in training for maximum performance. JAMA 205, 741-746. doi: 10.1001/jama.1968.031403700 43009

Fiskerstrand, A., and Seiler, K. S. (2004). Training and performance characteristics among Norwegian international rowers 1970-2001. Scand. J. Med. Sci. Sports 14, 303-310. doi: 10.1046/j.1600-0838.2003.370.x

Fritsch, W. (1985). Trainingssteuerung im Rudern. Rudersport 35, 80.
Fritsch, W. (1986). Die letzten Wochen vor dem Finale. Rudersport 36, 82.

Gaskill, S. E., Walker, A. J., Serfass, R. A., Bouchard, C., Gagnon, J., Rao, D. C., et al. (2001). Changes in ventilatory threshold with exercise training in a sedentary population: the HERITAGE Family Study. Int. J. Sports Med. 22, 586-592. doi: 10.1055/s-2001-18522

Guellich, A., and Seiler, K. S. (2010). Lactate profile changes in relation to training characteristics in junior elite cyclists. Int. J. Sports Physiol. Perform. 5, 316-327.

Guellich, A., Seiler, K. S., and Emrich, E. (2009). Training methods and intensity distribution of young world-class rowers. Int. J. Sports Physiol. Perform. 4, 448-460.

Hagerman, F. C., and Staron, R. E. (1982). Seasonal-variations among physiological variables in elite oarsmen. Med. Sci. Sports Exerc. 14, 142-142. doi: 10.1249/00005768-198202000-00193

Halson, S. L. (2014). Monitoring training load to understand fatigue in athletes. Sports Med. 44(Suppl. 2), S139-S147. doi: 10.1007/s40279-0140253-Z

Hardcastle, S. J., Ray, H., Beale, L., and Hagger, M. S. (2014). Why sprint interval training is inappropriate for a largely sedentary population. Front. Psychol. 5:1505. doi: 10.3389/fpsyg.2014.01505

Hartmann, U., Mader, A., and Hollmann, W. (1990). Heart rate and lactate during endurance training programs in rowing and its relation to the duration of exercise by top elite rowers. FISA Coach 1, 1-4.

Hawley, J. A., and Stepto, N. K. (2001). Adaptations to training in endurance cyclists: implications for performance. Sports Med. 31, 511-520. doi: 10.2165/00007256-200131070-00006

Holmberg, H. C. (1996). Träningslära Längd. Bjästa: CEWE-förlaget.

Ingham, S. A., Carter, H., Whyte, G. P., and Doust, J. H. (2008). Physiological and performance effects of low- versus mixed-intensity rowing training. Med. Sci. Sports Exerc. 40, 579-584. doi: 10.1249/MSS.0b013e3181 5 ecc6a

Ingham, S. A., Fudge, B. W., and Pringle, J. S. (2012). Training distribution, physiological profile, and performance for a male international 1500-m runner. Int. J. Sports Physiol. Perform. 7, 193-195.

Issurin, V. B. (2010). New horizons for the methodology and physiology of training periodization. Sports Med. 40, 189-206. doi: 10.2165/11319770-00000000000000

Joyner, M. J. (1991). Modeling: optimal marathon performance on the basis of physiological factors. J. Appl. Physiol. (1985) 70, 683-687.

Keith, S. P., Jacobs, I., and McLellan, T. M. (1992). Adaptations to training at the individual anaerobic threshold. Eur. J. Appl. Physiol. Occup. Physiol. 65, 316-323. doi: 10.1007/BF00868134

Kellmann, M. (2010). Preventing overtraining in athletes in high-intensity sports and stress/recovery monitoring. Scand. J. Med. Sci. Sports 20(Suppl. 2), 95-102. doi: 10.1111/j.1600-0838.2010.01192.x

Kiely, J. (2010). New horizons for the methodology and physiology of training periodization: block periodization: new horizon or a false dawn? Sports Med 40, 803-805; author reply: 805-807. doi: 10.2165/11535130-000000000-00000

Kiely, J. (2012). Periodization paradigms in the 21 st century: evidence-led or tradition-driven? Int. J. Sports Physiol. Perform. 7, 242-250.

Kindermann, W., Simon, G., and Keul, J. (1979). The significance of the aerobicanaerobic transition for the determination of work load intensities during endurance training. Eur. J. Appl. Physiol. Occup. Physiol. 42, 25-34. doi: 10.1007/BF00421101

Laursen, P. B. (2010). Training for intense exercise performance: high-intensity or high-volume training? Scand. J. Med. Sci. Sports 20(Suppl. 2), 1-10. doi: 10.1111/j.1600-0838.2010.01184.x

Laursen, P. B., and Jenkins, D. G. (2002). The scientific basis for highintensity interval training: optimising training programmes and maximising performance in highly trained endurance athletes. Sports Med. 32, 53-73. doi: 10.2165/00007256-200232010-00003

Lindsay, F. H., Hawley, J. A., Myburgh, K. H., Schomer, H. H., Noakes, T. D., and Dennis, S. C. (1996). Improved athletic performance in highly trained cyclists after interval training. Med. Sci. Sports Exerc. 28, 1427-1434. doi: 10.1097/00005768-199611000-00013

Londeree, B. R. (1997). Effect of training on lactate/ventilatory thresholds: a meta-analysis. Med. Sci. Sports Exerc. 29, 837-843. doi: 10.1097/00005768199706000-00016 
Lucia, A., Hoyos, J., Carvajal, A., and Chicharro, J. L. (1999). Heart rate response to professional road cycling: the Tour de France. Int. J. Sports Med. 20, 167-172. doi: 10.1055/s-1999-970284

Lucia, A., Hoyos, J., Pardo, J., and Chicharro, J. L. (2000). Metabolic and neuromuscular adaptations to endurance training in professional cyclists: a longitudinal study. Jpn. J. Physiol. 50, 381-388. doi: 10.2170/jjphysiol.50.381

Maughan, R. J., and Shirreffs, S. M. (2010). Development of hydration strategies to optimize performance for athletes in high-intensity sports and in sports with repeated intense efforts. Scand. J. Med. Sci. Sports 20(Suppl. 2), 59-69. doi: 10.1111/j.1600-0838.2010.01191.x

Mujika, I., Chatard, J. C., Busso, T., Geyssant, A., Barale, F., and Lacoste, L. (1995). Effects of training on performance in competitive swimming. Can. J. Appl. Physiol. 20, 395-406. doi: 10.1139/h95-031

Munoz, I., Seiler, K. S., Bautista, J., Espana, J., Larumbe, E., and EsteveLanao, J. (2014). Does polarized training improve performance in recreational runners? Int. J. Sports Physiol. Perform. 9, 265-272. doi: 10.1123/IJSPP.20 $12-0350$

Neal, C. M., Hunter, A. M., Brennan, L., O'Sullivan, A., Hamilton, D. L., De Vito, G., et al. (2013). Six weeks of a polarized training-intensity distribution leads to greater physiological and performance adaptations than a threshold model in trained cyclists. J. Appl. Physiol. (1985) 114, 461-471. doi: 10.1152/japplphysiol.00652.2012

Nolte, V. (1986). Trainingssteuerung-voraussetzungen, anwendung, grenzen. aufgezeigt am beispiel rudern. Leistungssport 16, 39-43.

Orie, J., Hofman, N., De Koning, J. J., and Foster, C. (2014). Thirty-eight years of training distribution in Olympic speed skaters. Int. J. Sports Physiol. Perform. 9, 93-99. doi: 10.1123/IJSPP.2013-0427

Plews, D. J., Laursen, P. B., Kilding, A. E., and Buchheit, M. (2014). Heartrate variability and training-intensity distribution in elite rowers. Int. J. Sports Physiol. Perform. 9, 1026-1032. doi: 10.1123/ijspp.2013-0497

Raglin, J. S. (1993). "Overtraining and staleness: psychometric monitoring of endurance athletes," in Handbook of Research on Sport Psychology, eds R. B. Singer, M. Murphey, and L. K. Tennant (New York, NY: Macmillan), 840-850.

Robinson, D. M., Robinson, S. M., Hume, P. A., and Hopkins, W. G. (1991). Training intensity of elite male distance runners. Med. Sci. Sports Exerc. 23, 1078-1082. doi: 10.1249/00005768-199109000-00013

Sandbakk, O., Holmberg, H. C., Leirdal, S., and Ettema, G. (2011). The physiology of world-class sprint skiers. Scand. J. Med. Sci. Sports 21, e9-e16. doi: 10.1111/j.1600-0838.2010.01117.x

Scharhag-Rosenberger, F., Meyer, T., Gassler, N., Faude, O., and Kindermann, W. (2010). Exercise at given percentages of VO2max: heterogeneous metabolic responses between individuals. J. Sci. Med. Sport 13, 74-79. doi: 10.1016/j.jsams.2008.12.626

Schumacher, Y. O., and Mueller, P. (2002). The 4000-m team pursuit cycling world record: theoretical and practical aspects. Med. Sci. Sports Exerc. 34, 1029-1036. doi: 10.1097/00005768-200206000-00020

Seiler, K. S. (2010). What is best practice for training intensity and duration distribution in endurance athletes? Int. J. Sports Physiol. 5, 276-291.

Seiler, K. S., and Kjerland, G. O. (2006). Quantifying training intensity distribution in elite endurance athletes: is there evidence for an "optimal" distribution? Scand. J. Med. Sci. Sports 16, 49-56. doi: 10.1111/j.1600-0838.2004.00418.x

Seiler, K. S., Joranson, K., Olesen, B. V., and Hetlelid, K. J. (2013). Adaptations to aerobic interval training: interactive effects of exercise intensity and total work duration. Scand. J. Med. Sci. Sports 23, 74-83. doi: 10.1111/j.16000838.2011.01351.x
Seiler, K. S., and Tonnessen, E. (2009). Intervals, thresholds, and long slow distance: the role of intensity and duration in endurance training. Sportscience $13,32-53$.

Sperlich, B., De Marees, M., Koehler, K., Linville, J., Holmberg, H. C., and Mester, J. (2011). Effects of 5 weeks of high-intensity interval training vs. volume training in 14-year-old soccer players. J. Strength Cond. Res. 25, 1271-1278. doi: 10.1519/JSC.0b013e3181d67c38

Steinacker, J. M. (1993). Physiological aspects of training in rowing. Int. J. Sports Med. 14(Suppl. 1), S3-S10.

Steinacker, J. M., Lormes, W., Kellmann, M., Liu, Y., Reissnecker, S., Opitz-Gress, A., et al. (2000). Training of junior rowers before world championships. Effects on performance, mood state and selected hormonal and metabolic responses. J. Sports Med. Phys. Fitness 40, 327-335.

Steinacker, J. M., Lormes, W., Lehmann, M., and Altenburg, D. (1998). Training of rowers before world championships. Med. Sci. Sports Exerc. 30, $1158-1163$.

Stepto, N. K., Hawley, J. A., Dennis, S. C., and Hopkins, W. G. (1999). Effects of different interval-training programs on cycling time-trial performance. Med. Sci. Sports Exerc. 31, 736-741. doi: 10.1097/00005768-199905000-00018

Stöggl, T., and Sperlich, B. (2014). Polarized training has greater impact on key endurance variables than threshold, high intensity, or high volume training. Front. Physiol. 5:33. doi: 10.3389/fphys.2014.00033

Takeshima, N., Tanaka, K., Kobayashi, F., Watanabe, T., and Kato, T. (1993). Effects of aerobic exercise conditioning at intensities corresponding to lactate threshold in the elderly. Eur. J. Appl. Physiol. Occup. Physiol. 67, 138-143. doi: 10.1007/BF00376657

Tonnessen, E., Sylta, O., Haugen, T. A., Hem, E., Svendsen, I. S., and Seiler, K. S. (2014). The road to gold: training and peaking characteristics in the year prior to a gold medal endurance performance. PLOS ONE 9:e101796. doi: 10.1371/journal.pone.0101796

Weston, A. R., Myburgh, K. H., Lindsay, F. H., Dennis, S. C., Noakes, T. D., and Hawley, J. A. (1997). Skeletal muscle buffering capacity and endurance performance after high-intensity interval training by well-trained cyclists. Eur. J. Appl. Physiol. Occup. Physiol. 75, 7-13. doi: 10.1007/s0042100 50119

Yoshida, T., Suda, Y., and Takeuchi, N. (1982). Endurance training regimen based upon arterial blood lactate: effects on anaerobic threshold. Eur. J. Appl. Physiol. Occup. Physiol. 49, 223-230. doi: 10.1007/BF02334071

Yu, H., Chen, X., Zhu, W., and Cao, C. (2012). A quasi-experimental study of Chinese top-level speed skaters. training load: threshold versus polarized model. Int. J. Sports Physiol. Perform. 7, 103-112.

Zapico, A. G., Calderon, F. J., Benito, P. J., Gonzalez, C. B., Parisi, A., Pigozzi, F., et al. (2007). Evolution of physiological and haematological parameters with training load in elite male road cyclists: a longitudinal study. J. Sports Med. Phys. Fitness 47, 191-196.

Conflict of Interest Statement: The authors declare that the research was conducted in the absence of any commercial or financial relationships that could be construed as a potential conflict of interest.

Copyright (๑) 2015 Stöggl and Sperlich. This is an open-access article distributed under the terms of the Creative Commons Attribution License (CC BY). The use, distribution or reproduction in other forums is permitted, provided the original author(s) or licensor are credited and that the original publication in this journal is cited, in accordance with accepted academic practice. No use, distribution or reproduction is permitted which does not comply with these terms. 